\title{
Effect of Single-Set Resistance Training on Quality of Life in COPD Patients Enrolled in Pulmonary Rehabilitation
}

\author{
Melissa J Benton PhD RN and Carolyn L Wagner RN
}

\begin{abstract}
BACKGROUND: Single-set resistance training (SSRT) improves strength and function in older adults with COPD. However, its effect on quality of life (QOL) has not been evaluated. This study evaluated the effect of SSRT on QOL in COPD patients enrolled in pulmonary rehabilitation (PR) and identified relationships between muscular strength, endurance and QOL. METHODS: Nineteen men and women (70.5 \pm 5.0 years old) with COPD completed 8 weeks of $P R$ alone or PR plus SSRT. QOL was measured using the Medical Outcomes Study Short Form 36. Upper and lower body strength was measured using chest and leg press, and lower body endurance was measured with the 6-min walk test. RESULTS: There were no significant differences in QOL between PR with versus without SSRT before or after PR. Both groups demonstrated significant improvements in QOL, including the Physical Function $(P=.02)$, Role Physical $(P=.002)$, Vitality $(P=.03)$, Social Functioning $(P=.03)$, and Mental Health $(P=.04)$ domains. Before $P R$, only lower body strength and endurance were significantly related to Physical Function $(r=0.53, P=.02$ and $\mathrm{r}=0.51, P=.03$, respectively). After the exercise program, upper body strength as well as lower body strength and endurance were significantly related to Physical Function $(r=0.57, P=.01$, $\mathrm{r}=0.51, P=.03$, and $\mathrm{r}=0.62, P=.005$, respectively), although improvements in Physical Function were predicted solely by improvements in upper body strength $(r=0.54, P=.02)$. CONCLUSIONS: The addition of SSRT to traditional PR does not affect overall improvements in QOL that are influenced primarily by an increase in upper body strength. Our findings suggest a threshold effect for exercise training, such that, once a threshold stimulus has been achieved, further improvements in QOL are not dose-dependent. Key words: pulmonary rehabilitation; short form 36; resistance training; endurance training. [Respir Care 2013;58(3):487-493. () 2013 Daedalus Enterprises]
\end{abstract}

\section{Introduction}

In the United States, mortality among adults with COPD is decreasing, ${ }^{1}$ and as a result the prevalence of COPD increases with age. ${ }^{2}$ As the number and age of older adults living with COPD increase, the need to maintain

Dr Benton is affiliated with the College of Nursing, Valdosta State University, Valdosta, Georgia. Ms Wagner is affiliated with Cardiopulmonary Rehabilitation, Banner Heart Hospital, Mesa, Arizona.

The authors have disclosed no conflicts of interest.

Correspondence: Melissa J Benton PhD RN, College of Nursing, Valdosta State University, 1500 North Patterson, Valdosta GA 31698. Email: mjbenton@valdosta.edu.

DOI: $10.4187 /$ respcare.01892 function and quality of life (QOL) becomes ever more important.

Among adults diagnosed with COPD, functional ability declines with age and is directly related to loss of muscle strength. ${ }^{3}$ The functional impairment that accompanies COPD has a direct and negative influence on QOL. ${ }^{4}$ Greater difficulty with activities of daily living is associated with greater feelings of dissatisfaction and, hence, diminished QOL. This is unfortunate, because QOL is not only an indicator of healthy aging, but declines in the physical component of QOL have been found to be predictive of early mortality. ${ }^{5}$

Functional status in COPD patients is directly influenced by exercise capacity. ${ }^{6}$ COPD patients are traditionally enrolled in pulmonary rehabilitation (PR) programs in an attempt to improve endurance and exercise performance, ${ }^{7}$ as well as physical well-being and QOL. ${ }^{8}$ Tradi- 
tional PR includes primarily endurance-type exercise training. ${ }^{9}$ However, this type of training may not maximize strength gains or necessarily translate into improvements in QOL. In fact, to prevent or reverse loss of muscle and strength, the American College of Sports Medicine has specifically recommended resistance training for older adults. ${ }^{10}$

Although the ability of resistance training to increase strength during PR has been well established, ${ }^{11,12}$ the effect on QOL is less clear. Recently, Janaudis-Ferreira and colleagues ${ }^{13}$ reported no improvements in QOL, using the Chronic Respiratory Disease Questionnaire, after 6 weeks of upper body resistance training, although Vonbank and colleagues $^{14}$ reported significant improvements in QOL, using the St George Respiratory Questionnaire, after 12 weeks of whole body resistance training. Based on these conflicting results, it would appear that both the duration of training and the amount of muscle stimulation provided may exert an influence on changes in QOL. Whole body training undoubtedly provides a greater opportunity for muscle stimulation than upper or lower body training alone. Furthermore, because the duration of PR programs is often limited to $<12$ weeks, in order to reduce costs and maximize resources, ${ }^{11}$ a shorter period of training would more accurately reflect real world conditions. It would therefore be of benefit to evaluate the effect of a brief program of whole body resistance exercise that could typically be incorporated into a traditional program of PR.

Single-set resistance training (SSRT) provides an opportunity for combining efficiency with effectiveness during PR. It has previously been found to improve strength and functional ability in older adults. ${ }^{15}$ Furthermore, when incorporated into an 8-week PR program, SSRT results in significantly greater increases in strength and function than endurance training alone. ${ }^{16}$ However, its influence on QOL has not yet been evaluated. Therefore, the purpose of this study was to evaluate the effect of SSRT on QOL in COPD patients enrolled in an 8-week, traditional PR program. A secondary purpose was to evaluate the relationship between muscular strength and endurance and the physical health component of QOL in this population.

\section{Methods}

A detailed description of recruitment and training procedures has previously been reported. ${ }^{16}$ Briefly, subjects were recruited at the time of their initial referral to an 8-week hospital-based PR program and had no previous exercise or rehabilitation experience. After completion of informed consent, they were randomized into either a traditional PR alone group or a PR plus SSRT group. Because randomization did not account for sex, the groups were not balanced as to male/female composition. Strength testing and training were incorporated into the regular PR

\section{QUICK LOOK}

\section{Current knowledge}

Pulmonary rehabilitation programs attempt to improve quality of life in patients with COPD through interventions to improve endurance and exercise performance. Recent guidelines suggest that resistance training is required to prevent muscle loss in older adults. Single-set resistance training improves strength in COPD patients.

\section{What this paper contributes to our knowledge}

The addition of single-set resistance training to traditional pulmonary rehabilitation did not improve quality of life in COPD subjects. Improvements in upper body strength associated with single-set resistance training were not dose-dependent.

sessions scheduled twice a week for the 8-week study period (a total of 16 sessions). The study was approved by the hospital and university institutional review boards for human subjects research.

\section{Subjects}

A total of 19 men $(n=5)$ and women $(n=14)$ with a diagnosis of COPD were included in the study (Table 1). Characteristically, they were elderly (age $70.5 \pm 5.0$ years), overweight (body mass index $27.4 \pm 4.9 \mathrm{~kg} / \mathrm{m}^{2}$ ), and met the Global Initiative for Chronic Obstructive Lung Disease criteria for stage III, severe, COPD. ${ }^{17}$

\section{Outcome Measures}

QOL was measured with the Medical Outcomes Study Short Form 36 (SF-36), a self-administered, Likert-scale tool that measures limitations in activities of daily living secondary to impairments in physical and mental health status. ${ }^{18}$ It has been validated for use with the elderly, ${ }^{19}$ and has specifically been used to describe QOL and outcomes of PR in COPD patients. ${ }^{20,21}$ The SF-36 consists of 36 questions in 2 domains (physical and mental health), with 8 subscales (Physical Function, Role Physical, Bodily Pain, General Health, Vitality, Social Function, Role Emotional, and Mental Health). Higher scores are indicative of greater QOL. The SF-36 was completed by all subjects prior to the first PR session and again after completion of the last PR session.

Muscular strength was measured using the one repetition maximal (1RM) incline chest press for upper body strength and the 1RM seated leg press for lower body strength. Maximal strength testing is the standard for 
Table 1. Participant Characteristics at Baseline

\begin{tabular}{lcc}
\hline \hline & $\begin{array}{c}\text { Pulmonary } \\
\text { Rehabilitation } \\
(n=9)\end{array}$ & $\begin{array}{c}\text { Pulmonary } \\
\text { Rehabilitation } \\
\text { Plus SSRT } \\
(n=10)\end{array}$ \\
\hline Male/female, no. & $1 / 8$ & $4 / 6$ \\
Age, $\mathrm{y}$ & $69.9 \pm 6.3$ & $71.0 \pm 3.7$ \\
Body weight, kg & $66.6 \pm 12.1$ & $80.0 \pm 16.3$ \\
BMI, kg/m ${ }^{2}$ & $26.1 \pm 3.9$ & $28.2 \pm 5.6$ \\
FEV, L & $0.74 \pm 0.4$ & $1.1 \pm 0.4$ \\
FEV,$\%$ predicted & $32.8 \pm 15.4$ & $42.0 \pm 8.5$ \\
FEV $/$ /FVC & $0.39 \pm 0.10$ & $0.52 \pm 0.13$ \\
Supplemental oxygen, no. & 6 & 3 \\
& & \\
\pm Values are mean \pm SD. There were no significant differences in anthropometrics or \\
pulmonary function between the groups. \\
SSRT $=$ single-set resistance training \\
BMI $=$ body mass index
\end{tabular}

strength measurement and for development of appropriate resistance training programs. ${ }^{22}$ It is safe and appropriate for strength measurement of adults diagnosed with COPD. ${ }^{23,24}$ All subjects completed 3 trials of 1RM testing. The first 2 trials were scheduled at the beginning of the first 2 PR sessions and included familiarization with the testing procedure. The third trial was scheduled at the beginning of the last PR session. Only one trial was used post-training, because subjects were already familiar with the exercises and testing procedure.

For the first trial, subjects were asked to complete a warm-up set of 10 repetitions using the lowest weight setting on the machine. The resistance was then increased $2.2-4.5 \mathrm{~kg}$ for upper body and $4.5-9.0 \mathrm{~kg}$ for lower body, and subjects completed a single repetition beginning at a $90^{\circ}$ angle of the elbows (chest press) and knees (leg press) through full extension of the arms and legs. Progressive weight was added until subjects could no longer complete one repetition. The 1RM for each trial was identified as the greatest weight lifted with good form. For the second trial, the warm-up set was calculated as $50 \%$ of the 1RM identified during the preceding trial, and the load for the first single attempt was set at $100 \%$ of the previous $1 \mathrm{RM}$ value. All testing and training were done using pin-loaded machines (Universal Gym Equipment, Cedar Rapids, Iowa) and supervised by research staff. To avoid the Valsalva maneuver, prior to each lift subjects were reminded to exhale during exertion (arm/leg extension) and inhale during relaxation (arm/leg flexion). Baseline 1RM values were calculated as the greatest weight lifted between trials 1 and 2 , while post-study values were taken as the 1RM identified in trial 3.

Muscular endurance was measured with the 6-min walk test (6MWT) prior to beginning the PR program, and again following the last PR session. The 6MWT is sensitive to functional improvements experienced by COPD patients as a result of PR, ${ }^{25,26}$ and has been found to be a strong predictor of mortality in this population. ${ }^{27}$ Program staff members conducted all 6MWT tests using standardized procedures. ${ }^{28,29}$ Briefly, subjects were asked to walk as quickly as possible for 6 min on a circular track, during which time they were given verbal encouragement at the end of each minute by supervising staff, using standardized language. If unable to continue due to fatigue, subjects were permitted to rest briefly and recommence the test at any time during the 6-min period. The total distance walked was used as the score for this test.

\section{Traditional Pulmonary Rehabilitation}

The PR program consisted of 16 sessions scheduled 2 non-consecutive days a week for 8 weeks. If subjects were unable to attend as scheduled, they were allowed to extend their PR until a total of 16 sessions had been completed. Training consisted of arm ergometry (Rehab Trainer, Monark, Vansbro, Sweden), treadmill walking (TM-210, Trackmaster Treadmills, Newton, Kansas), stationary cycling (Airdyne, Schwinn, Chicago, Illinois), and stepping (Total Body Recumbent Stepper, NuStep, Ann Arbor, Michigan), and was supervised by PR staff. Exercise intensity was initially set at 2-3 metabolic equivalents, based on the outcomes of the 6MWT and Duke Activity Status Index. ${ }^{30-32}$ Progression in time and intensity was based on perceived dyspnea ( $<4=$ somewhat severe) and perceived exertion $(<13=$ somewhat hard $)$. Subjects were encouraged to achieve a total duration of 20-40 min of exercise, using a combination of all equipment to ensure stimulation of both upper and lower body muscle groups. In addition, subjects were encouraged to perform one set of 6 exercises (wrist curl, arm curl, overhead arm extension, lateral raise, upright row, side bed), using handheld dumbbells that ranged in weight from 0.5 to $4.5 \mathrm{~kg}$. For each exercise the goal was to achieve 15 repetitions at a given weight before increasing the load at the next PR session. During exercise training, intensity was adjusted to maintain perceived exertion $<13$ (fairly hard) on a 20 point scale ${ }^{33}$ and perceived breathlessness $<4$ (moderate) on a 10 -point scale. ${ }^{34}$

\section{Single-Set Resistance Training}

The SSRT program consisted of a single set of 5 exercises (seated leg press, incline chest press, wide-grip back pulldown, biceps curl, triceps extension). A total of 13 PR sessions included SSRT due to the need to use 3 sessions for pre and post testing. Less than $10 \mathrm{~min}$ was required for the 5 exercises, so subjects were able to complete their full PR program without time constraints. The initial load for the leg and chest press was set at $50 \%$ of the baseline 
Table 2. Quality of Life, Measured With the Medical Outcomes Study Short Form 36, Before and After 8 Weeks of Pulmonary Rehabilitation or Pulmonary Rehabilitation Plus SSRT

\begin{tabular}{|c|c|c|c|c|}
\hline \multirow[b]{2}{*}{ Domain } & \multicolumn{2}{|c|}{$\begin{array}{l}\text { Pulmonary Rehabilitation, } \\
\text { mean } \pm \text { SD } \\
(n=9)\end{array}$} & \multicolumn{2}{|c|}{$\begin{array}{l}\text { Pulmonary Rehabilitation } \\
\text { Plus SSRT, mean } \pm \text { SD } \\
\quad(n=10)\end{array}$} \\
\hline & Before & After & Before & After \\
\hline \multicolumn{5}{|l|}{ Physical Health } \\
\hline Physical function & $26.2 \pm 4.1$ & $27.8 \pm 3.6^{*}$ & $27.8 \pm 7.7$ & $32.2 \pm 10.4 *$ \\
\hline Role physical & $27.2 \pm 6.5$ & $33.5 \pm 8.0 \dagger$ & $31.4 \pm 8.7$ & $36.5 \pm 9.5 \dagger$ \\
\hline Bodily pain & $49.0 \pm 7.4$ & $50.9 \pm 3.8$ & $51.9 \pm 12.5$ & $52.2 \pm 8.0$ \\
\hline General health & $34.8 \pm 6.0$ & $35.5 \pm 8.0$ & $37.0 \pm 9.7$ & $38.5 \pm 11.3$ \\
\hline \multicolumn{5}{|l|}{ Mental Health } \\
\hline Vitality & $39.3 \pm 12.7$ & $44.5 \pm 9.0 \ddagger$ & $41.5 \pm 5.9$ & $46.5 \pm 8.6 \ddagger$ \\
\hline Social function & $39.9 \pm 10.0$ & $43.5 \pm 8.7$ \$ & $41.6 \pm 13.3$ & $49.8 \pm 10.3 \ddagger$ \\
\hline Role emotional & $45.5 \pm 13.7$ & $43.4 \pm 13.3$ & $49.3 \pm 8.8$ & $46.2 \pm 11.3$ \\
\hline Mental health & $46.9 \pm 8.0$ & $51.3 \pm 4.9 \S$ & $50.6 \pm 7.5$ & $53.1 \pm 5.4 \S$ \\
\hline \multicolumn{5}{|c|}{$\begin{array}{l}\text { * Significantly different from baseline }\left(P=.02, \eta^{2}=0.28\right) \\
\dagger \text { Significantly different from baseline }\left(P=.002, \eta^{2}=0.45\right) \\
\text { † Significantly different from baseline }\left(P=.03, \eta^{2}=0.26\right) \\
\text { \& Significantly different from baseline }\left(P=.04, \eta^{2}=0.22\right) .\end{array}$} \\
\hline
\end{tabular}

1RM, while the other 3 exercises were set at a weight that allowed completion of 10 repetitions with good form and without undue fatigue (rating of perceived exertion $\leq 13$, "somewhat hard"). Subjects were asked to complete 8-12 repetitions of each exercise, and the load was increased at the subsequent session whenever subjects successfully achieved 10-12 repetitions of a given exercise.

\section{Statistical Analysis}

Data were analyzed using statistics software (SPSS 19.0, SPSS, Chicago, Illinois), with mean and standard deviation reported for all measurements. Significance was set at $P<.05$. Descriptive statistics were used to describe subject characteristics. Pre-post changes in QOL and muscular strength and endurance were evaluated using repeated measures analysis of variance, with a Bonferroni adjustment for multiple comparisons, with the mean difference significant at the .05 level. Effect size is expressed as $\eta^{2}$. An $\eta^{2}$ value of $<0.2$ was determined to be a small effect, a value of $0.2-0.8$ was considered a medium effect, and a value of $>0.8$ was considered a large effect. ${ }^{35}$ Pearson correlation analysis was used to identify relationships between strength, endurance, and QOL.

\section{Results}

All subjects completed all 16 PR sessions. There were no differences between groups at baseline for age, body weight, body mass index, or respiratory function (see Table 1), nor were any changes observed over the course of the 8-week study period. Furthermore, there were no between-group differences in perceived QOL either before or after the training program (Table 2). There were overall improvements in SF-36 scores for Physical Function (3.1 \pm 5.2 points, $P=.02)$, Role Physical $(5.7 \pm 6.5$ points, $P=.002)$, Vitality $(5.1 \pm 8.9$ points, $P=.03)$, Social Function $(6.0 \pm 10.6$ points, $P=.03)$, and Mental Health $(3.4 \pm 6.7$ points, $P=.04)$.

Prior to PR, strength and endurance were similar between the groups. Completion of PR, with or without SSRT, resulted in significant improvements in lower body muscular endurance (Table 3). As a whole, subjects increased their 6MWT distance by an overall average of $23 \%$, from $279.9 \pm 98.1 \mathrm{~m}$ to $345.1 \pm 92.5 \mathrm{~m}(P=.001)$, although between-group improvements in 6MWT were not statistically different $(P=.91)$. Significant time by group differences favoring the PR plus SSRT group were observed for both upper and lower body muscular strength. The PR plus SSRT group demonstrated a $10 \%$ increase in $1 \mathrm{RM}$ leg press $(P=.004)$ and a $14 \%$ increase in $1 \mathrm{RM}$ chest press $(P<.001)$, while the traditional PR group experienced small, nonsignificant reductions for both over the 8-week period.

Prior to commencement of exercise training, among all subjects, only lower body strength and endurance were significantly related to QOL. Baseline 1RM leg press and 6MWT scores were correlated with Physical Function scores on the SF-36 $(\mathrm{r}=0.53, P=.02$; and $\mathrm{r}=0.51$, $P=.03$, respectively). However, after the 8 -week program, upper body strength as well as lower body strength and endurance were correlated with Physical Function 
Table 3. Muscular Strength and Endurance Before and After 8 Weeks of Pulmonary Rehabilitation or Pulmonary Rehabilitation Plus SSRT

\begin{tabular}{|c|c|c|c|c|}
\hline & \multicolumn{2}{|c|}{$\begin{array}{l}\text { Pulmonary Rehabilitation, } \\
\text { mean } \pm \mathrm{SD} \\
(n=9)\end{array}$} & \multicolumn{2}{|c|}{$\begin{array}{l}\text { Pulmonary Rehabilitation } \\
\text { Plus SSRT, mean } \pm \text { SD } \\
\qquad(n=10)\end{array}$} \\
\hline & Before & After & Before & After \\
\hline One repetition maximal chest press, $\mathrm{kg}$ & $23.7 \pm 9.9$ & $22.34 \pm 8.9$ & $28.7 \pm 11.6$ & $32.8 \pm 12.4^{*}$ \\
\hline One repetition maximal leg press, $\mathrm{kg}$ & $79.1 \pm 24.7$ & $75.92 \pm 25.6$ & $92.5 \pm 41.5$ & $101.3 \pm 40.1 \dagger$ \\
\hline 6-min walk distance, $\mathrm{m}$ & $294.4 \pm 89.2$ & $359.0 \pm 70.7 \ddagger$ & $270.9 \pm 112.7$ & $339.0 \pm 112.9$ \\
\hline \multicolumn{5}{|c|}{$\begin{array}{l}\text { * Significantly different from baseline and from the pulmonary-rehabilitation-only group }\left(P<.001, \eta^{2}=0.61\right) \\
\dagger \text { Significantly different than baseline and from the pulmonary-rehabilitation-only group }\left(P=.004, \eta^{2}=0.41\right) \\
\text { † Significantly different from baseline }\left(P=.001, \eta^{2}=0.54\right)\end{array}$} \\
\hline
\end{tabular}

(r $=0.57, P=.01 ; \mathrm{r}=0.51, P=.03 ;$ and $\mathrm{r}=0.62$, $P=.005$, respectively). Despite this, improvements in Physical Function were found to be predicted only by improvements in upper body strength $(\mathrm{r}=0.54, P=.02)$.

\section{Discussion}

To our knowledge, this is the first study to evaluate the relatively limited stimulus provided by SSRT on QOL in a COPD population. Traditional PR provides a brief, moderately intensive exercise program that includes whole body muscle stimulus. Based on our results, it would appear that the additional stimulus provided by SSRT was not sufficient to promote additional gains in QOL over and above those that would be normally anticipated as a result of an 8-week PR program, despite the greater increases in muscular strength and endurance. This may indicate the existence of a threshold phenomenon for exercise training, such that once exercise of any type has achieved that threshold stimulus, further improvements in QOL are not dosedependent. A similar threshold has been identified for the effect of muscle strength on physical performance, ${ }^{36}$ such that strength gains above that threshold do not result in similar gains in functional ability.

The findings of Vonbank and colleagues ${ }^{14}$ support the existence of such a threshold. In agreement with the current study, they reported that, despite greater increases in strength induced specifically by resistance training, greater increases in QOL over and above those achieved by endurance training were not observed. It is important to note that the training volume, and hence the stimulus, of their resistance exercise program exceeded ours. Although both exercise protocols included 2 sessions per week, theirs was of longer duration (12 weeks) and included a multi-set program of 2-4 sets of 8 exercises. Furthermore, in addition to endurance training alone and a combined endurance/resistance training group, they included a resistance exercise alone group that, not surprisingly, demonstrated the greatest increases in overall strength. Yet despite the greater stimulus provided by their resistance training program, compared to ours, similar improvements in QOL were observed in all 3 groups. Greater increases in strength did not translate into greater increases in QOL.

Our findings are also in agreement with those of Dourado and colleagues, ${ }^{37}$ who compared the effects of exercise training on QOL in COPD patients over a 12 -week period. In this case, moderate-high intensity resistance training alone was compared with 2 combined training groups, both of which included walking plus resistance training at either moderate or low intensity. Both the resistance training alone group and the walking combined with moderate intensity resistance training group demonstrated significant increases in strength, yet all groups reported significant but similar increases in overall QOL. There was no effect of the greater between-group increases in strength on improvements in QOL. It would indeed appear that once a threshold stimulus is achieved for a general exercise program, there is no dose-response benefit of resistance training.

By comparison, our findings disagree with those of Janaudis-Ferreira and colleagues, ${ }^{13}$ who found no improvements in QOL after either 6 weeks of PR alone or PR combined with a specialized arm resistance training program. It is possible that the 6-week training period was insufficient to attain the threshold stimulus needed for a significant effect on QOL. In any case, despite significantly greater increases in upper body strength secondary to arm training plus PR, compared to PR alone, the additional stimulus provided solely by upper body resistance training was not sufficient to promote increases in QOL when no improvements secondary to PR alone were observed. This is somewhat surprising, given the mediating influence we observed specifically for upper body strength. It is possible that the difference in findings lies in the choice of measurement tools. Janaudis-Ferreira and colleagues measured QOL with the Chronic Respiratory Disease Questionnaire, ${ }^{38}$ which has a stronger emphasis on dyspnea and disease management than on physical func- 
tion. As such, it may not be as sensitive to overall functional changes secondary to exercise training as the SF-36, which includes a discrete physical function component. Had a more functionally oriented QOL tool been used, it is possible that increases in QOL similar to those reported by other researchers would have been observed.

A dose-response effect for PR on QOL has previously been suggested by Hassanein and Narsavage. ${ }^{21}$ Our results extend their findings by proposing a threshold effect, such that once a threshold exercise stimulus is achieved, further improvements in QOL are not dose-dependent. If so, identification of this threshold would be essential for developing efficient and effective resistance training programs for COPD patients.

The importance of upper body muscle strength in COPD patients has previously been reported by Dourado and colleagues. ${ }^{39}$ The results of our correlation analysis suggest that improvements in QOL associated with physical function are mediated by improvements in upper body rather than lower body function, since only changes in upper body strength were related to improvements in QOL after the PR program. Furthermore, the relationship was significant overall, despite the fact that the traditional PR group did not actually achieve significant improvements in strength. It is unclear whether this relationship is a direct effect of strength gains or that there is an unappreciated mediating influence of specific functional improvements related to activities of daily living. More research is needed.

Limitations to this study include its relatively small sample size. Nevertheless, our results are in agreement with other researchers, ${ }^{14,37}$ which supports the validity of our findings. In addition, due to the randomization process, the groups were not balanced as to sex. However, since there were no significant differences in QOL scores either before or after exercise training, when data were analyzed either by training groups or by sex (data not shown, $P=.10$ ), we do not believe that sex exerted an undue influence on our outcomes. Finally, the potential influence of the QOL instruments themselves on measurement outcomes should be recognized. Multiple tools have been used in this population to evaluate QOL. As previously discussed, our outcomes do not agree with those reported by JanaudisFerreira, ${ }^{13}$ using the Chronic Respiratory Disease Questionnaire. However, they are in agreement with Vonbank and colleagues ${ }^{14}$ and Dourado and colleagues, ${ }^{37}$ who evaluated QOL using the St George Respiratory Questionnaire. We chose to use the SF-36, which contains multiple domains reflecting both physical and psychosocial QOL and to further report individual domain scores for greater sensitivity. It is possible that the greater spectrum of the SF-36 allows it to capture elements of QOL reflected in the St George Respiratory Questionnaire, but not on the Chronic Respiratory Disease Questionnaire. More research in this area is evidently needed.

\section{Conclusions}

In conclusion, our findings do not support a short-term advantage of combining SSRT with traditional PR endurance-type exercise to achieve improvements in QOL. However, there may be unappreciated long-term advantages related to the influence of strength, and specifically upper body strength changes, on the physical health component of QOL. Clinical exercise programs for COPD patients should emphasize upper body training in particular, in order to capture these potential benefits.

\section{REFERENCES}

1. Ford ES, Mannino DM, Zhao G, Li C, Croft JB. Changes in mortality among United States adults with chronic obstructive pulmonary disease in two national cohorts recruited during 1971 through 1975 and 1988 through 1994. Chest 2011;141(1):101-110.

2. Akinbami LJ, Liu X. Chronic obstructive pulmonary disease among adults aged 18 and over in the United States, 1998-2009. NCHS Data Brief 2011(63):1-8.

3. Kapella MC, Larson JL, Covey MK, Alex CG. Functional performance in chronic obstructive pulmonary disease declines with time. Med Sci Sports Exerc 2011;43(2):218-24.

4. Katula JA, Rejeski WJ, Wickley KL, Berry MJ. Perceived difficulty, importance, and satisfaction with physical function in COPD patients. Health Qual Life Outcomes 2004;2:18.

5. Kroenke CH, Kubzansky LD, Adler N, Kawachi I. Prospective change in health-related quality of life and subsequent mortality among middle-aged and older women. Am J Public Health 2008;98(11):20852091.

6. Weaver TE, Richmond TS, Narsavage GL. An explanatory model of functional status in chronic obstructive pulmonary disease. Nurs Res 1997;46(1):26-31.

7. Weg JG. Therapeutic exercise in patients with chronic obstructive pulmonary disease. Cardiovasc Clin 1985;15(2):261-275.

8. Schoo AM. A literature review of rehabilitative intervention for chronic obstructive pulmonary disease patients. Aust Health Rev 1997;20(3):120-132.

9. Ries AL, Ellis B, Hawkins RW. Upper extremity exercise training in chronic obstructive pulmonary disease. Chest 1988;93(4):688-692.

10. American College of Sports Medicine. Position stand: exercise and physical activity for older adults. Med Sci Sports Exerc 2009;41(7): 1510-1530.

11. Ries AL, Bauldoff GS, Carlin BW, Casaburi R, Emery CF, Mahler DA, et al. Pulmonary rehabilitation: joint ACCP/AACVPR evidencebased clinical practice guidelines. Chest 2007;131(5 Suppl):4S-42S.

12. Nici L, Donner C, Wouters E, Zuwallack R, Ambrosino N, Bourbeau $\mathrm{J}$, et al. ATS/ERS statement on pulmonary rehabilitation. Am J Respir Crit Care Med 2006;173(12):1390-1413.

13. Janaudis-Ferreira T, Hill K, Goldstein RS, Robles-Ribeiro P, Beauchamp MK, Dolmage TE, et al. Resistance arm training in patients with COPD: a randomized controlled trial. Chest 2011;139(1):151158.

14. Vonbank K, Strasser B, Mondrzyk J, Marzluf BA, Richter B, Losch $\mathrm{S}$, et al. Strength training increases maximum working capacity in patients with COPD - randomized clinical trial comparing three training modalities. Respir Med 2012;106(4):557-563.

15. Galvao DA, Taaffe DR. Resistance exercise dosage in older adults: single- versus multiset effects on physical performance and body composition. J Am Geriatr Soc 2005;53(12):2090-2097. 


\section{Effect of Single-Set Resistance Training on Quality of Life in COPD Patients}

16. Phillips WT, Benton MJ, Wagner CL, Riley C. The effect of single set resistance training on strength and functional fitness in pulmonary rehabilitation patients. J Cardiopulm Rehabil 2006;26(5):330-337.

17. Rabe KF, Hurd S, Anzueto A, Barnes PJ, Buist SA, Calverley P, et al. Global strategy for the diagnosis, management, and prevention of chronic obstructive pulmonary disease: GOLD executive summary. Am J Respir Crit Care Med 2007;176(6):532-555.

18. Ware JE Jr, Sherbourne CD. The MOS 36-item short-form health survey (SF-36). I. Conceptual framework and item selection. Med Care 1992;30(6):473-483.

19. Lyons RA, Perry HM, Littlepage BN. Evidence for the validity of the Short-form 36 Questionnaire (SF-36) in an elderly population. Age Ageing 1994;23(3):182-184.

20. Tsara V, Serasli E, Katsarou Z, Tsorova A, Christaki P. Quality of life and social-economic characteristics of greek male patients on long-term oxygen therapy. Respir Care 2008;53(8):1048-1053.

21. Hassanein SE, Narsavage GL. The dose effect of pulmonary rehabilitation on physical activity, perceived exertion, and quality of life. J Cardiopulm Rehabil Prev 2009;29(4):255-260.

22. American College of Sports Medicine. Health-related physical fitness testing and interpretation, In: Thompson PJ, Gordon NF, Pescatello LS, editors. ACSM's guidelines for exercise testing and prescription. Philadelphia: Lippincott Williams \& Wilkins; 2010:60-104.

23. Robles PG, Mathur S, Janaudis-Fereira T, Dolmage TE, Goldstein RS, Brooks D. Measurement of peripheral muscle strength in individuals with chronic obstructive pulmonary disease: a systematic review. J Cardiopulm Rehabil Prev 2011;31(1):11-24.

24. Benton MJ, Swan PD. Addition of resistance training to pulmonary rehabilitation programs: an evidence-based rationale and guidelines for use of resistance training with elderly patients with COPD. Cardiopulm Phys Ther J 2006;17(4):127-133.

25. Spencer LM, Alison JA, McKeough ZJ. Six-minute walk test as an outcome measure: are two six-minute walk tests necessary immediately after pulmonary rehabilitation and at three-month follow-up? Am J Phys Med Rehabil 2008;87(3):224-228.

26. Gerald LB, Sanderson B, Redden D, Bailey WC. Chronic obstructive pulmonary disease stage and 6-minute walk outcome. J Cardiopulm Rehabil 2001;21(5):296-299.

27. Pinto-Plata VM, Cote C, Cabral H, Taylor J, Celli BR. The 6-min walk distance: change over time and value as a predictor of survival in severe COPD. Eur Respir J 2004;23(1):28-33.
28. Guyatt GH, Sullivan MJ, Thompson PJ, Fallen EL, Pugsley SO, Taylor DW, Berman LB. The 6-minute walk: a new measure of exercise capacity in patients with chronic heart failure. Can Med Assoc J 1985;132(8):919-923.

29. American Thoracic Society. Guidelines for the six-minute walk test. Am J Respir Crit Care Med 2002;166(1):111-117.

30. Phillips L, Wang JW, Pfeffer B, Gianos E, Fisher D, Shaw LJ, Mieres JH. Clinical role of the Duke Activity Status Index in the selection of the optimal type of stress myocardial perfusion imaging study in patients with known or suspected ischemic heart disease. J Nucl Cardiol 2011;18(6):1015-1020.

31. Hamilton DM, Haennel RG. Validity and reliability of the 6-minute walk test in a cardiac rehabilitation population. J Cardiopulm Rehabil 2000;20(3):156-164.

32. Bairey Merz CN, Olson M, McGorray S, Pakstis DL, Zell K, Rickens CR, et al. Physical activity and functional capacity measurement in women: a report from the NHLBI-sponsored WISE study. J Womens Health Gend Based Med 2000;9(7):769-777.

33. Borg G. Perceived exertion as an indicator of somatic stress. Scand J Rehabil Med 1970;2(2):92-98.

34. Noble BJ, Borg GA, Jacobs I, Ceci R, Kaiser P. A category-ratio perceived exertion scale: relationship to blood and muscle lactates and heart rate. Med Sci Sports Exerc 1983;15(6):523-528.

35. Gravetter FJ, Wallnau LB. Introduction to hypothesis testing, In: Gravetter FJ, Wallnau LB. Statistics for the behavioral sciences, 8th edition. Belmont, CA: Wadsworth; 2008:229-279.

36. Jette AM, Assmann SF, Rooks D, Harris BA, Crawford S. Interrelationships among disablement concepts. J Gerontol A Biol Sci Med Sci 1998;53(5):M395-M404.

37. Dourado VZ, Tanni SE, Antunes LC, Paiva SA, Campana AO, Renno AC, Godoy I. Effect of three exercise programs on patients with chronic obstructive pulmonary disease. Braz J Med Biol Res 2009; 42(3):263-271

38. Guyatt GH, Berman LB, Townsend M, Pugsley SO, Chambers LW. A measure of quality of life for clinical trials in chronic lung disease. Thorax 1987;42(10):773-778.

39. Dourado VZ, Antunes LC, Tanni SE, de Paiva SA, Padovani CR, Godoy I. Relationship of upper-limb and thoracic muscle strength to 6-min walk distance in COPD patients. Chest 2006;129(3):551557. 